\title{
Estado-Avaliador: reflexões sobre sua evolução no Brasil
}

Evaluator State: some thoughts on its development in Brazil

Estado-Evaluador: reflexiones sobre su evolución en Brasil

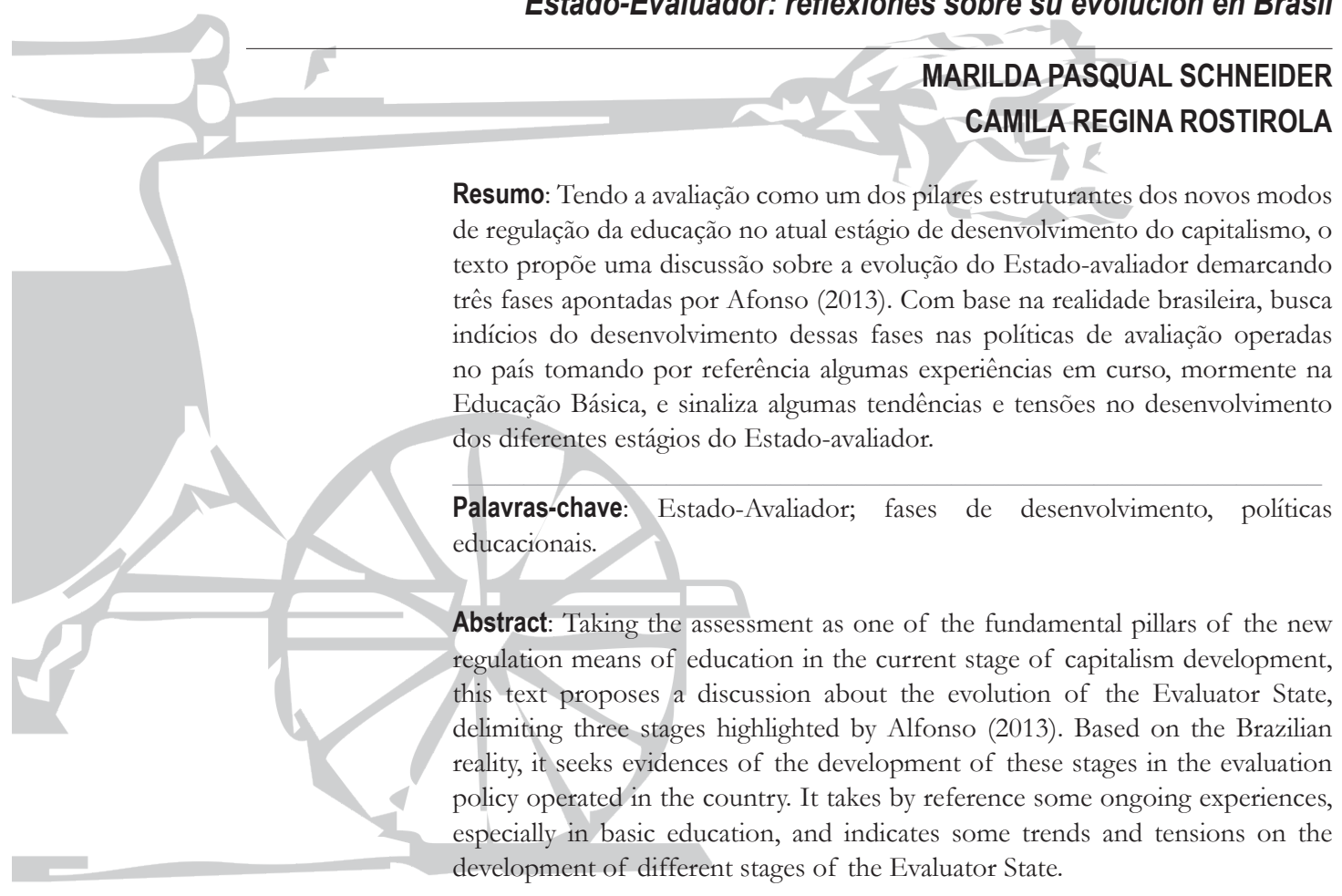

Keywords: Evaluator State; Stages of development; Educational policies.

Resumen: Teniendo la evaluación como uno de los pilares estructurantes de los nuevos modos de reglamentación de la educación en la actual etapa del desarrollo del capitalismo, el texto propone una discusión sobre la evolución del EstadoEvaluador demarcando tres fases apuntadas por Afonso (2013). Teniendo como base la realidad brasilera, busca indicios del desarrollo de estas fases en las políticas de evaluación operadas en el país usando como referencia algunas experiencias en curso, especialmente en la educación básica y señala algunas tendencias y tensiones en el desarrollo de las diferentes etapas del Estado-Evaluador.

Palabras clave: Estado-Evaluador; fases de desarrollo; políticas educacionales. 


\section{INTRODUÇÃO}

Desde os anos de 1980, vimos assistindo a um cenário de mudanças nas formas como o Estado se interpõe para implementar e controlar alguns setores da sociedade. Um dos eixos estruturantes dessas reformas tem sido a introdução, consolidação e ampliação de mecanismos de avaliação de largo espectro como instrumento da ação dos governos na produção e regulação das políticas públicas. No campo educacional, a utilização de provas (para estudantes, escolas e professores) tornou-se, nas últimas décadas, peça principal das estratégias empreendidas pelo Estado visando a direcionar mudanças no setor. $\mathrm{Na}$ senda de vários autores, é possível afirmar que as políticas de avaliação implementadas nas últimas três décadas têm sido responsáveis pela adoção de mecanismos de um quase-mercado na educação, a partir dos quais se concretiza a remodelação do papel do Estado na condução das políticas públicas e da atuação das escolas e redes de ensino frente ao processo ensino-aprendizagem.

Dada a centralidade das avaliações como estratégia para assegurar determinado referencial de qualidade, sociólogos do campo afirmam que estamos presenciando a conformação de nova fase nos desdobramentos do papel do Estado, denominada Estado avaliador (AFONSO, 2009; NEAVE, 2001; BALL, 2004). Em sentido amplo, essa expressão significa que o Estado passou a admitir "a lógica do mercado, através da importação para o domínio público de modelos de gestão privada, com ênfase no resultado e nos produtos dos sistemas educativos." (AFONSO, 2009, p. 49). Trata-se, na visão do autor, de um novo darwinismo social, que tem na avaliação um dos pontos centrais das recentes reformas na administração pública.

Sob os auspícios dessa onda avaliativa, a agenda de reformas de muitos países vem marcada por novos e cada vez mais sofisticados dispositivos de aferição do desempenho das escolas e estudantes, que incluem desde mecanismos criados no âmbito local, conhecidos por avaliações em larga escala, até transnacionais, que informam diferentes estágios do Estado avaliador. Suas reconfigurações do Estado-avaliador atenderiam ao interesse de assegurar a continuidade do projeto capitalista no contexto da globalização, tendo a avaliação como "um dos eixos estruturantes das reformas da administração pública (AFONSO, 2013, p. 271).

Em revisita às características do Estado-avaliador, Afonso (2013) reconhece três estágios (fases) na adoção de sistemas de avaliação no campo da educação, desenvolvidos ao longo das três últimas décadas (1980-2010). Embora distintos, o autor considera a possibilidade de coexistência desses estágios no momento atual.

O primeiro estágio seria marcado pela vinculação da ideologia neoliberal

494 - RBPAE - v. 31, n. 3, p. 493 - 510 set./dez. 2015 
às políticas de avaliação e accountability e pelo incremento de mecanismos de avaliação de larga escala em contexto nacional. O segundo, pela aderência dos países a formas de avaliação internacional, e, o terceiro, o estágio atual, pelos processos de transnacionalização da prática avaliativa.

Apesar de ainda com contornos "fluidos e incertos", esse terceiro estágio caracterizar se-ia pelo impacto de formas de avaliação comparada, especialmente em países periféricos e semiperiféricos que, "seduzidos por ímpetos de progresso (ou de desenvolvimento)" (AFONSO, 2013, p. 276), estariam espelhando-se em países mais desenvolvidos e competitivos para promover reformas especialmente na educação superior. No caso de países mais avançados, a despeito de a comparação não deixar de existir, ela seria motivada por outras razões, cujos impactos, no entanto, seriam igualmente perversos.

Considerando as repercussões nas injunções do Estado-avaliador em países como o Brasil, buscamos neste texto deslindar características dessas três fases, apontando tendências e tensões ao mesmo tempo em que procuramos reconhecer indícios de sua presença nas políticas de avaliação educacional praticadas no Brasil. As reflexões efetuadas tomam a tese de Afonso sobre os estágios de desenvolvimento do Estado-avaliador como hipótese central e procuram ajustar as lentes de análise para a realidade brasileira, tomando por referência algumas evidências sobre as formas de avaliação em curso no Brasil, mormente na educação básica.

\section{ASCENSÃO E DESENVOLVIMENTO DO ESTADO-AVALIADOR}

Partindo do pressuposto de que quão mais próxima a gestão dos serviços públicos estiver de seu usuário maior será o controle e a fiscalização, a partir dos anos de 1980, ganharam corpo reformas destinadas a promover a modernização do Estado, especialmente nas formas de conceber e realizar o controle dos serviços públicos. Mudanças administrativas gerenciais empreendidas desde então justificaram a emergência de um Estado menos pesado e mais fraco nas questões de mercado, mais forte, no entanto, no tocante às políticas de corte social.

As mudanças no modelo de administração pública repercutiram no setor educacional onde passou-se a defender a necessidade de maior transparência por parte de escolas confluindo para a entrada de processos de avaliação, prestação de contas e responsabilização (accountability) também nesse setor. Como consequência dessas mudanças, o Estado passou a fiscalizar e avaliar os resultados obtidos em testes externos (à escola e ao país) impulsionando uma espécie de competição entre as instâncias sob seu domínio.

A exemplo do que ocorrera no campo econômico, as reformas encetadas 
no campo educacional tiveram como marco referencial a conformação da educação às leis que regem o mercado e a iniciativa privada. Pressupostos da qualidade total, da competitividade, da eficiência e eficácia foram importados do sistema econômico para as práticas educativas e pedagógicas. A educação passou a ser regida por leis que configuram o que alguns autores têm vindo a designar de mecanismos de um quase-mercado educacional, porquanto sua introdução nesse campo teve como maior consequência a diminuição das fronteiras entre o setor público e o privado.

Afonso (1999) considera que as estratégias adotadas no campo da educação nas últimas décadas podem ser chamadas de estratégias de mercado "porque substituem o monopólio dos fornecedores do Estado por uma diversidade de fornecedores independentes e competitivos" (p.115). Mas são quase "porque diferem dos mercados convencionais em aspectos importantes" (Ibidem.) Um desses aspectos é que, embora tenha em vista o cliente, as organizações assim denominadas não visam à maximização de seus lucros. Outro aspecto refere-se ao fato de que "o poder de compra dos consumidores não é necessariamente expresso em termos monetários e, em alguns casos, os consumidores delegam em certos agentes a sua representação no mercado" (Ibidem).

É nesse contexto que surge a designação Estado-avaliador, posto que os países adotaram instrumentos de acompanhamento do desempenho das escolas com "a finalidade de reorientar políticas públicas" (FREITAS, 2011, p.47). A avaliação educacional, nesse sentido, representa uma estratégia de governação em que o Estado atua a partir dos resultados obtidos em testes organizados e realizados, primeiramente, pelo próprio país e, num segundo momento, por agências multilaterais. Tem a ver, portanto, com o fortalecimento de referenciais neoliberais, representados pela adesão a medidas políticas e administrativas ajustadas às leis do mercado e pela sofisticação dos mecanismos de controle e responsabilização dos resultados obtidos pelos sistemas educacionais.

Para Neave (apud BALL, 2004), um dos primeiros estudiosos a se valer dessa categorização, a terminologia Estado-avaliador é compatível com as mudanças geradas pela crise que assolou a economia mundial na década de 1980 e a crescente necessidade de elaborar instrumentos mais sofisticados para aferir a qualidade da educação superior. Seu surgimento revela um contexto educacional politicamente ambivalente. Isso porque no Estado-avaliador não são abandonadas as "velhas tradições" do modelo burocrático weberiano de controle do poder estatal (LIMA, 2011, p.35), próprias das práticas de governação que marcaram as décadas precedentes. O Estado continua a praticar um modelo de administração centralizado, aparentemente contraditório quando comparado aos preceitos neoliberais de administração pública, mas também adota formas de 
regulação e controle da educação que discursivamente evocam a participação e a desconcentração do poder.

$\mathrm{Na}$ esteira de autores como Afonso (1999; 2009; 2010), Freitas (2011; 2012), Lima (2011), Nóvoa (2010), dentre outros, afirmamos que esse novo papel assumido na condução das políticas educacionais assevera as já profundas desigualdades sociais, principalmente por induzir, dentre outras coisas, à homogeneização (dos currículos, da organização das escolas e dos projetos educativos), à competição (entre e intra escolas) e à seletividade (dos mais aptos e mais bem preparados). Essas consequências tornam mais distantes as possibilidades de melhoria da qualidade enquanto pretexto para a criação e ampliação das políticas nacionais de avaliação educacional.

A despeito dos efeitos pouco consistentes no que toca à melhoria educacional, já demonstrados por vários autores - e a obra de Ravitch (2011) ${ }^{1}$ constitui um dos mais expressivos exemplos - as políticas de avaliação passaram a constituir "um dos eixos estruturantes das reformas da administração pública" (AFONSO, 2013, p. 271) ao longo das últimas décadas, tendo sido marcadas por características distintas. Seriam essas características que, segundo o autor, tornam possível reconhecer diferentes estágios do Estado-avaliador.

O primeiro estágio teria tido expressão na década de 1980 e seria caracterizado pela expansão das políticas de avaliação em larga escala dentro de cada país, como estratégia de administração pública no contexto das reformas neoliberais empreendidas pelos estados nacionais. Esse primeiro estágio caracteriza-se, ainda, pela "introdução de mecanismos de accountability baseados em testes estandardizados de alto impacto e em rankings escolares, indutores de formas autoritárias de prestação de contas e de responsabilização das instituições." (Idem, p.272)

O baixo desempenho escolar obtido por estudantes norte-americanos na década de 1980 passou a ser constantemente associado à ineficiência das políticas educacionais da primeira série de reformas promovidas pelo governo Reagan e à falta de financiamentos públicos. Declarada a intenção de reverter o quadro indesejável da educação americana, no seu segundo mandato. Reagan (1986 a 1989) deu início a um conjunto de reformas visando a aumentar o controle sobre a educação pública.

Nos governos americanos que sucederam Reagan, aos processos de avaliação em larga escala foram associadas políticas de accountability. Coerente com os novos mecanismos de regulação, ganharam merecido destaque, especialmente

\footnotetext{
1 Em sua obra "Vida e morte do grande sistema escolar americano", traduzida para o português em 2011, a autora denuncia que o modelo de avaliação adotado pelos Estados Unidos, que inspira o Brasil, não contribuiu para melhorar a educação no país.
} 
em países de capitalismo central, as práticas avaliativas conexas a estratégias de responsabilização e prestação de contas, como é o caso das políticas de accountability (BALL, 2004), que já haviam consolidado seus sistemas nacionais de avaliação e centravam suas ações educacionais em preceitos culturais performativos.

Afonso (2013) destaca que, em seu primeiro estágio, a adoção de políticas de avaliação "dependeu, em grande medida, de uma (ainda) expressiva autonomia relativa de Estados enquanto unidades de uma Federação" (p .271). Isso porque sua implementação tinha a ver com as leituras que os países faziam da realidade local, mesmo nos casos em que era possível verificar a influência de instâncias supranacionais nas políticas nacionais.

O segundo estágio é caracterizado pela "construção de um sistema de indicadores e de avaliação comparada internacional em larga escala" (Idem, p. 274), protagonizada em boa medida pela "presença crescente e incontornável" de organizações internacionais na criação de políticas nacionais para a educação. Esse estágio teria adquirido expressão nos anos de 1990, com a entrada da Organização para a Cooperação e Desenvolvimento Econômico (OCDE) no campo das avaliações internacionais o que favoreceu, no âmbito dos países, uma "aparente consensualidade" (Idem, 2008, p.14) legitimadora da eficácia da avaliação.

Atualmente, uma variedade de testes são aplicados nacionalmente e regionalmente nos países participantes das avaliações internacionais, evidenciando a imersão desses países em uma prática de regulação mercantil que, na visão de Barroso (2003, p. 83), não é resultado apenas “da nova conjuntura política (governo de maioria centro-direita), mas principalmente de um contexto internacional favorável a este tipo de regulação".

Com a internacionalização das políticas avaliativas, o segundo estágio culminaria, portanto, com uma "retração crescente da autonomia relativa do Estado-nação e maior protagonismo de instâncias internacionais e transnacionais" (Idem, 2013, p.278).

A despeito de a comparação não significar transposição direta ou, simplesmente, "empréstimo de políticas" internacionais dado estarem submetidas aos processos de reinterpretação e recriação no contexto da prática (BALL; BOWE, 1992), organismos multilaterais, como a OCDE e o Banco Mundial, por exemplo, vêm atuando incisivamente na disseminação de "boas práticas", com o argumento de "melhorar a qualidade dos governos e dos sistemas educativos". As comparações, nesse sentido, constituíram uma outra estratégia de governança, abrindo as portas para a construção de certa consensualidade no uso das avaliações.

De acordo com Nóvoa (2010, p. 35), as avaliações comparadas estariam sendo disseminadas por organizações que, por usufruírem de prestígio internacional, passariam a atuar no sentido de estabelecer "pontos de referência" 
e "práticas de comparação" como "forma principal da política." No âmbito europeu, a "lógica de comparações contínuas" teria como apelo discursivo a pretensa intenção de "encontrar as soluções mais proveitosas ou eficientes" acerca das políticas estatais servindo, por isso, como "um mecanismo para legitimar a ingerência da União Europeia nos temas educativos nacionais" (Ibidem) dos Estados-membro.

Para Afonso (2013), a expansão das práticas de avaliação comparada indica o surgimento de um terceiro estágio nas políticas de avaliação, o "pósEstado-avaliador". Apesar de apresentar "ainda contornos pouco definidos", é no âmbito do ensino superior onde a hipótese do Pós-Estado-avaliador poderia ser mais facilmente percebida, ainda que não exclusivamente.

Conforme acentua, essa terceira fase

Quer justamente acentuar a ideia de que, para muito além das agendas nacionais e dos efeitos externos da globalização sobre os diferentes países, o que está em curso é uma estratégia de exacerbação e diversificação de lógicas neoliberais de transnacionalização da educação, com ênfase na privatização, mercadorização e mercantilização. (Idem, p. 276)

Assim, o terceiro estágio pós-Estado-avaliador seria marcado pela ampliação de formas de avaliação comparada entre países as quais estabeleceriam pontos de referência que, supostamente, constituiriam a garantia de qualidade educacional para os países. A comparabilidade representaria uma estratégia para influenciar a determinação de políticas que permitissem maior regulação internacional do capitalismo. As formas de avaliação em larga escala, já presentes no modelo de Estado-avaliador, estariam, portanto, mais acentuadas no terceiro estágio de governação e disseminariam a ideia de novo momento na regulação e creditação do campo educacional, cada vez mais distante do âmbito nacional.

Essa nova conformação indica a emergência de um Estado que não mais se limita a avaliar, mas que, em sua fase mais auspiciosa, promove a seletividade nacional e internacional, legitimando as desigualdades e homogeneizando processos educativos pela via de avaliações sistêmicas e globais. Essas seriam, portanto, as prováveis repercussões da face mais contemporânea do Estadoavaliador na sua relação com a educação.

\section{DESENVOLVIMENTO DO ESTADO-AVALIADOR NO BRASIL}

A primeira experiência de avaliação em larga escala com o uso de "testes padronizados, de aplicação externa, com foco nos estudantes, nas escolas, nas redes e ou nos sistemas de ensino" (DURLI; SCHNEIDER, 2011, p. 172) ocorreu 
no Brasil no ano de 1976, sob a batuta da Coordenação de Aperfeiçoamento do Pessoal de Nível Superior (Capes).

Essa experiência tinha por principal objetivo monitorar o corpo docente das instituições de ensino superior. Nas duas décadas seguintes, com a adesão do Brasil aos pressupostos da ideologia neoliberal, o período foi especialmente pródigo para o aperfeiçoamento dessa prática. Foi então que se deu início ao delineamento de um sistema nacional de avaliação, sob a alegação de que o país "carecia de informações sobre o processo de ensino e o impacto das políticas educacionais" (OLIVEIRA, 2012, p. 150).

Começava-se, assim, uma nova fase na gestão dos serviços públicos no Brasil voltada especialmente ao controle das instituições, à redução dos custos e ao aumento da eficiência dos serviços prestados. Segundo Oliveira (2012), essa nova fase teria o sistema de avaliação como "base da regulação empreendida pelo Estado-avaliador" (p.150) no país.

A tentativa de constituição de um sistema nacional de avaliação e, mais tarde, também com a finalidade de accountability, adentraram as principais discussões educacionais e, sob forte influência estatal, foram paulatinamente firmando espaço em meio às principais legislações nacionais sob o apelo de melhoria da qualidade educativa, de descentralização administrativa e autonomia das instituições de ensino.

A implantação do Sistema de Avaliação da Educação Básica (Saeb), no ano de 1990, a partir de uma demanda do Banco Mundial, é exemplo cabal da entrada do Brasil nos preceitos do Estado-avaliador e das injunções de organizações internacionais sobre as políticas nacionais. Reestruturado no ano de 1995 e, posteriormente, em 2005, sob a alegação de que na forma como vinha sendo realizado não dava conta de retratar a realidade escolar do país ${ }^{2}$, o Saeb abriu espaço para a realização de avaliações censitárias com dados sobre a situação educacional das escolas e redes de ensino, constituindo-se em importante instrumento para o aprimoramento das políticas educacionais aos moldes praticados pelos países mais avançados.

Coerentes com os pressupostos do Estado-avaliador, várias iniciativas de avaliação da Educação Básica foram desenvolvidas por estados e municípios brasileiros ao longo dos anos de 1990, algumas delas precursoras do Saeb como é o caso do Programa de Avaliação do Desempenho da Rede Pública Escolar do Estado de Pernambuco, criado em 1991; dos Programas de Avaliação das Escolas

2 Quando de sua criação, o Saeb realizava avaliações amostrais representativas da situação educacional de estudantes dos estados brasileiros, não permitindo colher dados por escola. A recolha por amostra probabilística da situação educacional do país estendeu-se até o ano de 2005 quando, pela Portaria n. 931 , de 21 de março, o sistema foi expandido, passando a constituir-se por dois processos de avaliação: Avaliação Nacional da Educação Básica (Aneb) e Avaliação Nacional do Rendimento Escolar (Anresc), conhecida por Prova Brasil. 
da Rede Estadual de Minas Gerais e do Rendimento Escolar dos Alunos de $4^{\mathrm{a}}$ e $8^{\mathrm{a}}$ séries do Ceará, ambos criados em 1992; do Sistema de Avaliação do Rendimento Escolar do Estado de São Paulo (SARESP), iniciado em 1996, dentre outros.

Além dos programas criados no âmbito dos estados da federação, diversos municípios passaram a desenvolver sistemas próprios de avaliação. Em levantamento acerca de iniciativas municipais de avaliação desde o início dos ciclos avaliativos pelo Estado, no ano de 1990, Bauer et.al (2015, p. 4) identificaram 1.573 municípios com propostas próprias de avaliação, “concebidas, em geral, por profissionais integrantes das redes de ensino, sejam técnicos (77\%) ou professores e/ou gestores da rede $(82 \%)$ ".

O maior crescimento em termos de número de municípios que constituíram sistemas próprios de avaliação deu-se entre os anos de 2005 a 2013. Nesse período, houve 1.257 novas iniciativas. Apesar de muitos recorrerem a assessorias externas para a elaboração de suas propostas, seja por meio de consultorias independentes, empresas especializadas ou universidades, (Idem), sabe-se que o Saeb é a fonte inspiradora da maioria delas tanto no âmbito dos estados da federação como dos municípios.

Dadas suas características, consideramos que o Saeb compreende uma primeira fase do Estado-avaliador no Brasil. No entanto, diferente do que ocorreu em outros países, em que esse primeiro estágio seria representado também pela associação entre processos de accountability e políticas de avaliação, no caso brasileiro, esse processo demorou um pouco mais, tendo ocorrido de forma mais sistemática somente a partir de 2005, com ampliação da abrangência do Saeb.

Segundo Fernandes e Gremaud (2009), somente a partir da divulgação de estratos censitários por escola e redes de ensino, disponibilizados com a criação da Anresc (Prova Brasil), o Brasil passou a contar com um programa de accountability, ainda que fraco, para a Educação Básica. Este, no entanto, restrito ao Ensino Fundamental, posto que a avaliação da Prova Brasil não atinge censitariamente o Ensino Médio.

A entrada da accountability no Ensino Médio teria ocorrido com as mudanças no Exame Nacional de Ensino Médio (Enem), realizadas também no ano de 2005. As reformulações operadas permitiram ampliar a abrangência do exame tornando-o instrumento para ingresso no Ensino Superior e para acesso às bolsas do Prouni. Foi a partir dessas alterações que, segundo os autores, o Enem teria passado a ser uma avaliação também com finalidades de accountability.

Bonamino e Franco (1999) consideram que a introdução de processos de accountability na educação brasileira faz parte do segundo ciclo de avaliações em larga escala criado no Brasil, quando estas passaram a ser articuladas com políticas de responsabilização. Como vimos, no caso brasileiro, a introdução de 
ferramentas de accountability ocorreu em momento posterior ao da criação de um sistema nacional de avaliação em larga escala. Pertence, portanto, a uma segunda geração das políticas de avaliação nacional implementadas no Brasil.

O passo definitivo para a introdução de processos de accountability na Educação Básica deu-se mesmo em 2007, com a criação do Índice de Desenvolvimento da Educação Básica (Ideb), hoje considerado “o principal indicador de accountability do país." (FERNANDES; GREMAUD, 2009, p. 231). Esse índice combina dados de rendimento escolar, obtidos a partir dos resultados da Prova Brasil, com as taxas de aprovação de uma determinada série a cada dois anos. Com a aprovação do PNE para o período 2014-2014, o Ideb foi alçado à condição de uma política de Estado declarada na meta 7 do Plano (NARDI, 2014).

Graças à sua fórmula de composição, o Ideb alçou a Prova Brasil ao status de avaliação majoritária na aferição e monitoramento do desempenho escolar de estudantes de Educação Básica. A atribuição de metas por escola, projetadas a partir das aferições bianuais da Prova Brasil, evidencia o esforço empreendido pelo país na implantação de políticas educacionais com finalidades de accountability permitindo conformar o primeiro estágio do Estado-avaliador. Com as mudanças operadas no sistema de avaliação a partir de 2005, o papel do Estado passou a ser o de regulação e controle, associado, contraditoriamente, ao discurso da descentralização, democratização da gestão pública e autonomia das escolas e dos sistemas educativos.

A entrada no segundo estágio do Estado-avaliador, assim caracterizado em vista de alguns países, após o desenvolvimento de seus sistemas próprios de avaliação, terem aderido a programas internacionais de avalição comparada, parece ter seguido caminhos pouco convergentes com as tendências internacionais. Isso porque, enquanto na Europa e nos Estados Unidos as avaliações comparadas internacionais ganharam vulto somente após a consolidação dos sistemas nacionais, no Brasil ocorreu o contrário: foram as avaliações internacionais e, em alguns casos, em perspectiva comparada, que serviram de referência para a criação de um sistema próprio de avaliação. Por conta disso, consideramos que, no Brasil, o segundo estágio do Estado-avaliador desenvolveu-se pari passu ao primeiro, confundindo-se ou mesmo, em alguns momentos, antecipando-se a este.

De fato, o Programme for International Student Assessment (Pisa), desenvolvido em nosso país pela OCDE desde o ano 2000, com o objetivo de realizar avaliações comparadas entre estudantes na faixa dos 15 anos, inspirou tanto a reformulação do Saeb como a criação do Ideb, consideradas políticas que deram impulso ao desenvolvimento de processos de accountability na educação brasileira. Consoante apontamos, embora o Saeb já estivesse implantado desde 1990 foi somente a 
partir de 2005, com a introdução de avaliações censitárias, que seus resultados puderam ser utilizados como instrumento de responsabilização das escolas.

O Pisa avalia as áreas de Leitura, Matemática e Ciências, a cada três anos. Em cada ano de avaliação é dada maior ênfase a uma das áreas. Dada sua modalidade de organização, inquirição e publicação, esse Programa

\footnotetext{
Incorpora e expressa modos de pensar e de fazer interiorizáveis, para que eles se percebam capacitados para participar 'naturalmente' no exercícios de monitoração e comparação internacional, tomados estes como práticas correntes e apropriadas às suas identidades e papeis (CARVALHO, 2009, p. 1023)
}

Trata-se, segundo Carvalho (idem) "de uma avaliação comparada internacional das performances dos escolares que vem se afirmando, ao longo da presente década, como um dos principais meios de ação da OCDE no campo educativo" (p. 1010) Seus organizadores intentam que o Programa seja reconhecido como "ponto de passagem obrigatório para um debate e uma decisão política centrados em evidências científicas” (p. 1029).

Um dos elementos centrais do Pisa é a construção de uma política transnacional na qual os Estados nacionais voluntariamente se envolvem. Os dados coletados por esse Programa, juntamente com os do Ideb, servem de parâmetro e orientação para a implementação de ações no âmbito do Estado brasileiro, nomeadamente na definição e produção de políticas para a Educação Básica. Trata-se, portanto, de uma avaliação externa ao país com forte influência no delineamento de políticas nacionais.

Ainda que tenha sido o projeto de "maior amplitude" (CASTRO, 2002, p. 6) a que o Brasil aderiu antes de reformular o Saeb, o Pisa não foi a primeira iniciativa adotada em termos de estudos comparados internacionais. Em 1997, o país foi convidado a ingressar no Projeto World Education Indicator (WEI), promovido pela Unesco em parceria com a OCDE. Essa parceria representou importante oportunidade de se "conhecer e produzir indicadores seguindo parâmetros técnicos já consolidados em estudos internacionais comparados." (CASTRO, 2002, p. 3). Trata-se de programa destinado à produção de dados estatísticos com vistas à formulação de políticas públicas para o desenvolvimento dos países membros na área da educação e à realização periódica de estudos comparativos internacionais.

Outro programa comparado de avaliação a que o Brasil aderiu em 1997 é o desenvolvido pelo Laboratório Latino-americano de Avaliação da Qualidade da Educação (LLECE). O laboratório é coordenado pela Organização das Nações Unidas para a Educação, Ciência e a Cultura (Unesco), em conjunto com a Oficina Regional de Educação para a América Latina e Caribe (Orealc) e 
desenvolve estudos comparativos sobre a aprendizagem de alunos de países da América Latina em séries específicas. Por seu caráter regional e por avaliar séries específicas, os estudos desenvolvidos pelo LLECE têm sido bem aceitos pelos países latino-americanos.

O Primeiro Estudo Regional Comparativo e Explicativo (Perce), aplicado pelo LLECCE em 1997, avaliou o desempenho de alunos de $3^{\mathrm{a}}$ e $4^{\mathrm{a}}$ séries do Ensino Fundamental em linguagem, matemática e fatores associados a esses desempenhos. Essa foi a primeira experiência em estudos comparados sobre a aprendizagem de alunos de países da América Latina, tendo sido considerado uma das maiores conquistas políticas da década para os países da região. No Brasil, as provas foram aplicadas por amostragem em escolas públicas e privadas do Rio Grande do Sul, Minas Gerais e Ceará, que representavam os níveis I, II e III do IDH daquele ano (UNESCO, 2001).

O Segundo Estudo Regional Comparativo e Explicativo (Serce) foi realizado no ano de 2006 e avaliou o desempenho dos estudantes da $3^{\mathrm{a}}$ e $6^{\mathrm{a}}$ séries do Ensino Fundamental da América Latina em matemática, linguagem, ciências e fatores associados. Além de equipes de avaliadores, esse projeto contou com a participação de pedagogos, especialistas em currículo e peritos na construção de instrumentos, técnicos e monitores latino-americanos na definição do desenho, implantação e análise dos instrumentos de avaliação oferecendo, inclusive, subsídios para os sistemas nacionais dos países envolvidos.

O Terceiro Estudo Regional Comparativo (Terce) foi desenvolvido no ano de 2013 com uma amostra representativa de alunos de $4^{a}$ e $7^{a}$ séries do Ensino Fundamental, de cada um dos países participantes, nas mesmas disciplinas da segunda avaliação. Nessa terceira edição, o desempenho dos estudantes brasileiros em matemática ( $4^{\mathrm{a}}$ série) e leitura ( $7^{\mathrm{a}}$ série) foi significativamente superior à média dos países, sendo que nas demais disciplinas (leitura - $4^{a}$ série; matemática e ciências - $7^{\mathrm{a}}$ série) o desempenho ficou equiparado ao dos demais países participantes (TERCE, 2014).

A possibilidade de participação no processo de elaboração dos instrumentos de avaliação bem como o fato de os países obterem subsídios para o aperfeiçoamento de seus sistemas nacionais baseados em evidências e, ainda, de a avaliação contemplar módulos nacionais de fatores associados ao rendimento de aprendizagem constituem os mais fortes argumentos utilizados pelo Brasil para justificar sua participação nas avaliações promovidas pelo LLECCE. Outro argumento refere-se a que este é o único laboratório que realiza análise sobre a aprendizagem escrita nos países da América Latina.

Como podemos constatar, está em causa a construção de um referencial internacional de qualidade pautado em análises em perspectiva comparada com 
países cujas condições educacionais são próximas do ponto de vista geográfico. Essas evidências concordam com as características do segundo estágio do Estadoavaliador apontadas por Afonso (2013), mas também podem indicar nuances que poderiam antever o desdobramento de uma terceira fase que estaria, nesse caso, caracterizada pela ampliação de agências de avaliação em conexão internacional e o "incremento de políticas de avaliação comuns no âmbito de blocos regionais como a União Europeia ou o Mercado Comum do Sul (Mercosul)” (p. 278).

De fato, afora esta, outras iniciativas de avaliação comparada patrocinadas pelos fóruns de cooperação bilateral, no âmbito do Mercosul, da Cúpula das Américas e da Oficina Regional de Educação da Unesco para a América Latina e o Caribe (OREALC) têm conquistado a adesão do Brasil, demonstrando que, a exemplo de países situados no continente europeu, os novos modos de governação tendem a basear-se em "lógicas de contrato e redes de trabalho, fortemente respaldadas por dados, avaliações, resultados, pontos de referência, boas práticas e aprendizagem mútua" (NÓVOA, 2010, p. 36 - tradução nossa). Tais iniciativas vêm sendo intensificadas tanto nos países mais desenvolvidos como no âmbito dos blocos regionais da América Latina.

Especificamente em relação aos acordos bilaterais com países do $\mathrm{Mercosul}^{3}$, existem atualmente vários programas financiados pelo governo brasileiro em parceria com países-membros, os quais abrangem desde o fomento a projetos conjuntos de pesquisa no âmbito da pós-graduação, intercâmbios de estudantes de graduação e professores, até o fortalecimento de cursos de pósgraduação. Dentre as ações apontadas, destaca-se a criação do "Espaço Regional de Educação Superior do Mercosul”, no ano de 2006, no qual o Brasil figura como um dos protagonistas com o lançamento da Universidade Latino-Americana (UNILA) e do Instituto Mercosul de Estudos Avançados (IMEA) (BRASIL, 2008).

Ainda que não se restrinjam a processos de avaliação comparada, esses acordos são evidências do interesse do Brasil na internacionalização da educação brasileira, especialmente no ensino superior. Mas eles impõem alguns compromissos que tanto conectam o país com as tendências da globalização como com as políticas nacionais. Para poder participar dos programas de avaliação internacional, o Brasil precisa assegurar um currículo mínimo comum aos países participantes. Como consequência, veem-se favorecidas as condições de comparabilidade internacional com vistas a aumentar a competitividade econômica.

3 Atualmente, Argentina, Brasil, Uruguai, Paraguai e Venezuela são membros plenos do Mercosul; Chile, Bolívia, Colômbia, Equador e Peru são associados; e Nova Zelândia e México são países observadores. 
Como podemos constatar, são inúmeras as iniciativas de avaliação em curso no Brasil tanto em perspectiva nacional como também internacional. Essas iniciativas corroboram a tese de estágios distintos na conformação e desenvolvimento do Estado-avaliador, ainda que sobrepostos ou subjacentes uns aos outros. A variedade de experiências instiga diferentes olhares, seja em termos das políticas produzidas a partir delas, das teorias que as sustentam como das metodologias e modelos que as informam, posto que muitas caminham na contramão das teorizações pedagógicas construídas ao longo do século XX.

Com as medidas em curso, o Brasil confirma seu interesse em inserir-se cada vez mais na implementação de políticas públicas de avaliação para o setor educacional. espelhando-se em experiências de outros países, especialmente os mais avançados, tendo em vista aceder a patamares mais elevados de desenvolvimento econômico.

\section{CONSIDERAÇÕES FINAIS}

Alimentado pela lógica capitalista vincada em novo modelo de administração pública, o Estado-avaliador confirma sua centralidade no controle da educação pela incorporação de novas e mais sofisticadas estratégias de avaliação. Assentado no desejo de maximização dos lucros, o Estado-avaliador experimenta formatos que intensificam a expansão de políticas de mercadorização da educação em contexto que extrapola a esfera nacional.

$\mathrm{Na}$ senda das reflexões tecidas por Afonso (2013) e aqui tomadas como referência, foi possível reconhecer nitidamente, no Brasil, a presença de um primeiro estágio do Estado-avaliador, caracterizado principalmente pela expansão de práticas avaliativas padronizadas acedidas no pretenso objetivo de promover a melhoria da qualidade em todas as etapas e modalidades de ensino da educação brasileira.

Além da Prova Brasil e do Ideb, que cumprem o intento de implementação de uma política de accountability educacional e, portanto, corroboram o fortalecimento desse primeiro estágio, outras formas de avaliação seguem sendo adotadas na educação brasileira, promovendo novas e mais sofisticadas estratégias de regulação da educação pública em âmbito nacional e internacional.

Essas iniciativas vêm sendo desenvolvidas pelo Instituto Nacional de Estudos e Pesquisas Educacionais (Inep), que, a partir de 1997, passou a ter, dentre suas principais incumbências, a de "planejar, orientar e coordenar o desenvolvimento de sistemas e projetos de avaliação educacional, visando [a] o estabelecimento de indicadores de desempenho das atividades de ensino no país", bem como de "organizar o sistema de informações e estatísticas, com o 
objetivo de subsidiar a formulação de políticas educacionais dos governos federal, estaduais e municipais." (BRASIL, 2003).

A adesão ao Pisa e às formas de avaliação internacional constituem evidências inquestionáveis da entrada do Brasil em um segundo estágio do Estado-avaliador. Com esse e outros programas de estudos comparados, o país capitalizou sua participação na construção de um ambiente cultural e político pautado no intercâmbio de experiências de comparabilidade internacional.

As formas de avaliação postuladas por programas promovidos no âmbito dos países da América Latina e Caribe foram também inspiradoras da criação de políticas avaliativas para todos os níveis e modalidades de ensino ao mesmo tempo em que possibilitaram a apropriação, pelo Brasil, de uma metodologia de recolha de dados passível de ser comparada. Por meio dessas iniciativas, práticas de avaliação seguem sendo ampliadas e intensificadas no país sob os desígnios de uma educação global.

Apesar de ainda com contornos difusos, algumas características de um terceiro estágio também são possíveis de se verificar mais contemporaneamente no Brasil. Dentre algumas evidências, destacamos a tendência ao afunilamento e modularização do currículo pela adoção de matrizes de referência e escalas de proficiência para os testes de largo espectro, à padronização curricular para fins de comparabilidade e à ampliação de práticas avaliativas conexas a agências regionais.

Não restam dúvidas, portanto, de que, em termos de tendências e tensões na evolução nos estágios de desenvolvimento do Estado-avaliador, o Brasil vem traçando um caminho apoiado em experiências internacionais, principalmente no tocante ao desenho das políticas em curso. Esperamos, entretanto, que as experiências malogradas dos países centrais possam servir de referência para a reorientação das políticas nacionais tendo em vista recuperar o caráter pedagógico das avaliações perdido com a massificação de testes padronizados.

\section{REFERÊNCIAS}

AFONSO, Almerindo Janela. Mudanças no Estado-avaliador: comparativismo internacional e teoria da modernização revisitada. Revista Brasileira de Educação, v.18, n.53, p. 267-284, abr/jun. 2013.

- Um olhar sociológico em torno da accountability em educação. In: ESTEBAN, Maria Teresa; AFONSO, Almerindo Janela (Orgs.). Olhares e interfaces: reflexões críticas sobre a avaliação. São Paulo: Cortez, 2010. p. 147170. 
Avaliação educacional: regulação e emancipação. 4.ed. São Paulo: Cortez, 2009.

- Para uma crítica da avaliocracia. OPS! Revista de Opinião Socialista, Lisboa, n. 2, p. 14-16, nov. 2008.

. Estado, mercado, comunidade e avaliação: Esboço para uma rearticulação crítica. Educação \& Sociedade, ano XX, n. 69, dez. 1999.

BALL, Stephen J. Performatividade, privatização e o pós-Estado do bem-estar. Educação \& Sociedade, Campinas, v. 25, n.89, p. 1105-1126, set/dez. 2004.

BOWE, Robert. Subject departments and the "implementation" of National Curriculum policy: an overview of the issues. Journal of Curriculum Studies, London, v.24, n. 2.p. 07-115. 1992.

BARROSO, João. Organização e regulação dos ensinos básico e secundário, em Portugal: sentidos de uma evolução. Educação \& Sociedade, Campinas, SP, v. 24, n.82, p. 63-92, abr. 2003.

BAUER, Adriana... [et.al.]. Iniciativas de avaliação do Ensino Fundamental em municípios brasileiros: mapeamento e tendências. Anais... 37 Reunião Nacional da ANPEd, Florianópolis, 2015. Disponível em: http://37reuniao.anped.org. br/wp-content/uploads/2015/02/Trabalho-GT13-3716.pdf. Acesso em: 09 ago.2015.

BONAMINO, Alícia; FRANCO, Creso. Avaliação e política educacional: o processo de institucionalização do Saeb. Cadernos de Pesquisa, n. 108, p. 101132, nov.1999.

BRASIL. Ministério da Educação. Relatório 2005-2007. Assessoria Internacional. Gabinete do Ministro. Brasília, 2008. Disponível em: http://portal.mec.gov.br/ ai/arquivos/pdf/ relatorio2005_07.pdf Acesso em: 25 março.2015.

Portaria MEC no. 2.255, de 25 de agosto de 2003. Aprova o regimento interno do Inep. Diário Oficial da União, 26 ago. 2003. 
CARVALHO, Luís Miguel. Governando a educação pelo espelho do perito: uma análise do Pisa como instrumento de regulação. Educação \& Sociedade, Campinas, vol. 30, n.109, p.1009-1036, set./dez. 2009.

CASTRO, Maria Helena Guimarães. A participação do Brasil em estudos e avaliações educacionais comparadas internacionais. 2002. Disponível em: <http:// dominiopublico.gov.br/download/texto/mre000095.pdf> Acesso em: 07 nov.2014.

DURLI, Zenilde; SCHNEIDER, Marilda Pasqual. Regulação do currículo no Ensino Fundamental de 9 anos. Contrapontos, Itajaí, v.11, n. 2, p. 170-178, maio/ago. 2011.

FERNANDES, Reynaldo; GREMAUD, Amaury. Qualidade da educação: avaliação, indicadores e metas. In: VELOSO, F. et al. (Orgs.). Educação básica no Brasil: construindo o país do futuro. Rio de Janeiro: Elsevier, 2009. p. 213238.

FREITAS, Luiz Carlos de. Os reformadores empresariais da educação: de desmoralização do magistério à destruição dos sistema público de educação. Educação \& Sociedade, Campinas, v.33, n.119, p.376-404, abr.jun.2012.

FREITAS, Luiz Carlos de et.al. Avaliação educacional: caminhando pela contramão. 3.ed. Petrópolis, RJ: Vozes, 2011.

LIMA, Licínio C. Administração escolar: estudos. Porto: Porto Editora, 2011.

NARDI, Elton Luiz. Políticas de responsabilização e PNE: tendência, ensaio e possibilidades. Revista Retratos da Escola, Brasilia, v. 8, n.15, p. 231-246, jul./ dez. 2014.

NEAVE, Guy. Reconsideración del estado avaliador. In: NEAVE, Guy. Educación superior: histórica e política. Barcelona: Gedisa, 2001. p. 211-240.

NÓVOA, António. La construcción de um espacio educativo europeo: governando a través de los datos y la comparación. Revista Española de Educación Comparada, 16, p. 23-42, 2010. 
OLIVEIRA, Ana Paula de Matos. Avaliação e Regulação da Educação: a prova Brasil como política de regulação da rede pública do Distrito Federal. Brasillia: Liber Livro, 2012.

RAVITCH, Diane. Vida e morte do grande sistema escolar americano: como os testes padronizados e o modelo de mercado ameaçam a educação. Porto Alegre: Sulina, 2011.

TERCE. Terceiro Estudo Regional Comparativo e Explicativo: fatores associados Brasil. 2014. Disponível em:<http://portal.inep.gov.br/terce $>$. Acesso em: ago.2015.

UNESCO. Primer estúdio internacional comparativo: sobre lenguaje, matemática y factores associados, para alunos del tercer y quarto grado de la educación básica. Laboratorio Latinoamericano de Evaluación de la Calidad de la Educación. Informe Técnico, Unesco, agosto de 2001. Disponível em: $<$ download/internacional/all/Primeiro_Estudo_comparativo_LLECE.pdf $>$ Acesso em: ago.2015.

MARILDA PASQUAL SCHNEIDER é pós-doutora em política educativa pela Universidade do Minho. Professora do programa de Pós-graduação em Educação da Universidade do Oeste de Santa Catarina. E-mail: marilda.schneider@unoesc. edu.br

CAMILA REGINA ROSTIROLA é mestre em educação pela Universidade do Oeste de Santa Catarina. Professora da Rede Municipal de Ensino. E-mail: milarostirola@hotmail.com 